Review

\title{
The economic cost of hospital malnutrition in Europe; a narrative review
}

\author{
Saman Khalatbari-Soltani ${ }^{\text {a, b }}$, Pedro Marques-Vidal ${ }^{\text {b, * }}$ \\ a Institute of Social and Preventive Medicine (IUMSP), Lausanne University Hospital, Biopole 2, Route de la Corniche 10, CH-1010 Lausanne, Switzerland \\ ${ }^{\mathrm{b}}$ Department of Internal Medicine, Lausanne University Hospital (CHUV), Rue du Bugnon 46, 1011 Lausanne, Switzerland
}

\section{A R T I C L E I N F O}

Article history:

Received 21 January 2015

Accepted 15 April 2015

\section{Keywords:}

Malnutrition

Prevalence

Length of hospital stay

Cost

Narrative review

\begin{abstract}
A B S T R A C T
Background: Malnutrition among hospitalized patients increases length of stay (LOS) and carries extra hospitalization costs.

Objective: To review the impact of malnutrition on hospital LOS and costs in Europe.

Methods: PubMed and Google Scholar search. All articles from January 2004 until November 2014 were identified. Reference lists of relevant articles were also manually searched.

Results: Ten studies on LOS and nine studies on costs were reviewed. The methods used to assess malnutrition and to calculate costs differed considerably between studies. Malnutrition led to an increased LOS ranging from 2.4 to 7.2 days. Among hospitalized patients, malnutrition led to an additional individual cost ranging between $1640 €$ and $5829 €$. At the national level, the costs of malnutrition ranged between 32.8 million $€$ and 1.2 billion $€$. Expressed as percentage of national health expenditures, the values ranged between $2.1 \%$ and $10 \%$.

Conclusions: In Europe, malnutrition leads to an increase in LOS and in hospital costs, both at the individual and the national level. Standardization of methods and results reported is needed to adequately compare results between countries.
\end{abstract}

(c) 2015 European Society for Clinical Nutrition and Metabolism. Published by Elsevier Ltd. All rights reserved.

\section{Introduction}

Malnutrition is a highly prevalent problem among hospitalized patients and leads to a considerable adverse health and financial burden $[1,2]$. Estimates for the worldwide prevalence of malnutrition range between 20 and $50 \%$ of hospitalized patients, depending on the population under study and the nutritional screening tools used [3].

Hospital malnutrition is a result of a complex relation between disease, food and nutrition [4]. According to the European Society for Parental and Enteral Nutrition (ESPEN), malnutrition consists of

Abbreviation: LOS, length of stay; ESPEN, European Society for Parental and Enteral Nutrition; DRM, disease related malnutrition; NRS, Nutritional Risk Screening; SGA, Subjective Global Assessment; NRI, Nutritional Risk Index; MUST, Malnutrition Universal Screening Tool; BMI, Body Mass Index; DRG, diagnosisrelated group.

* Corresponding author. Department of Internal Medicine, Room BH10-642, Lausanne University Hospital (CHUV), Rue du Bugnon 46, 1011 Lausanne, Switzerland. Tel.: +41213140934.

E-mail addresses: Saman.KhalatbariSoltani@unil.ch (S. Khalatbari-Soltani), Pedro-Manuel.Marques-Vidal@chuv.ch (P. Marques-Vidal). both over- and under-nutrition but in this study only undernutrition will be considered [3]. Indeed, under-nutrition, also known as disease related malnutrition (DRM), is an urgent public health problem in Europe [5]. Hospital malnutrition has been shown to increase morbidity and LOS, to delay recovery and therefore to result in higher health care and hospital costs [6-8]. Just in Europe, it has been estimated that 20 million patients are at the risk of malnutrition, with an annual cost up to 120 billion $€$ $[9,10]$. Notwithstanding its impact on health, the economic impact of hospital malnutrition has seldom been studied. In a period where health costs containment is a necessity, better identification of the factors associated with increasing hospitalization costs is paramount to optimize health care delivery. Thus, we aimed to review the impact of hospital malnutrition on LOS and health costs in Europe.

\section{Methods}

\section{Literature search strategy}

A literature search was conducted in November 2014 using PubMed (MEDLINE) and Google Scholar electronic databases. The 
search terms used are summarized in supplementary file. All relevant studies published between January 2004 and November 2014 reporting the associations between malnutrition among hospitalized patients and LOS or cost were evaluated. The following key terms included "prevalence", "length of stay", "cost" in combination with "hospital malnutrition" and "hospital undernutrition".

Studies were included if they were a) published from 2004 onwards, as older studies might not correspond to current standards of malnutrition screening and health care delivery and as costs no longer corresponded to current ones; b) conducted among adults ( $\geq 18$ years old), with no upper age limit; c) conducted in any European country, as universal health coverage is available for most European countries and health expenditures would not be influenced by individual or third party payers; and d) had an English/ French/German/Spanish/Portuguese abstract, as other languages could not be assessed by the authors or colleagues. Duplicate publications (i.e. reporting the results of the same study) were excluded.

\section{Data extraction}

Titles of articles were analyzed for selecting potentially relevant studies. Then, the abstract and the full text were examined in terms of the eligibility criteria, and the references were also searched for other potential studies not covered by the search strategy.

Data on study characteristics (author, title, country and publication year), study duration, number of patients, prevalence of malnutrition, LOS and/or costs related to malnutrition were extracted by SK, and further confirmed by PMV. Main summary measures were LOS and/or costs related to malnutrition. Both individual (i.e. patient) and overall (i.e. for the whole country) costs were considered. As costs were expressed in different currencies, conversion to Euros $(€)$ was performed using the rates of November 4th, 2014 as indicated in www.xe.com/ currencyconverter.

\section{Results}

Impact of malnutrition on length of stay

Ten papers were included (selection procedure on Fig. 1). Their main characteristics are summarized in Table 1 . Three studies were from Germany [7,11,15], three from Spain [12-14], two from Switzerland [15,16], one from Portugal [6], one from France [17] and one from Norway [18]. Seven studies were multidisciplinary, i.e. conducted in different medical departments [6,11-15,18]; the remaining were conducted in a gastroenterology ward [7], in a cancer center [17] and in an internal medicine department [16]. One article had data on LOS according to malnutrition status, but it was unclear which definition was applied, so it was not included; LOS was $6.3 \pm 4.7$ for well nourished and $10.6 \pm 12.0$ for malnourished patients, respectively [19].

Four studies used the Nutritional Risk Screening (NRS-2002) $[6,13,14,18]$, three used the Subjective Global Assessment (SGA) $[7,11,12]$, one used both SGA and NRS-2002 [16], one used the Nutritional Risk Index (NRI) [15] and one study did not report the tools [17]. Prevalence of malnutrition ranged from 19 [7] to $42 \%$ [6]. These results are in agreement with a review of malnutrition prevalence in England since 1994 (range 11-45\%) [20] and with a collaborative multicentre study including 12 Europe and Middle East countries (32\% overall) [21].

In all studies, LOS was significantly longer in malnourished than in well-nourished patients, the differences ranging from 2.4 [12] to 7.2 days [13] (Table 1 ). Two studies reported a positive association

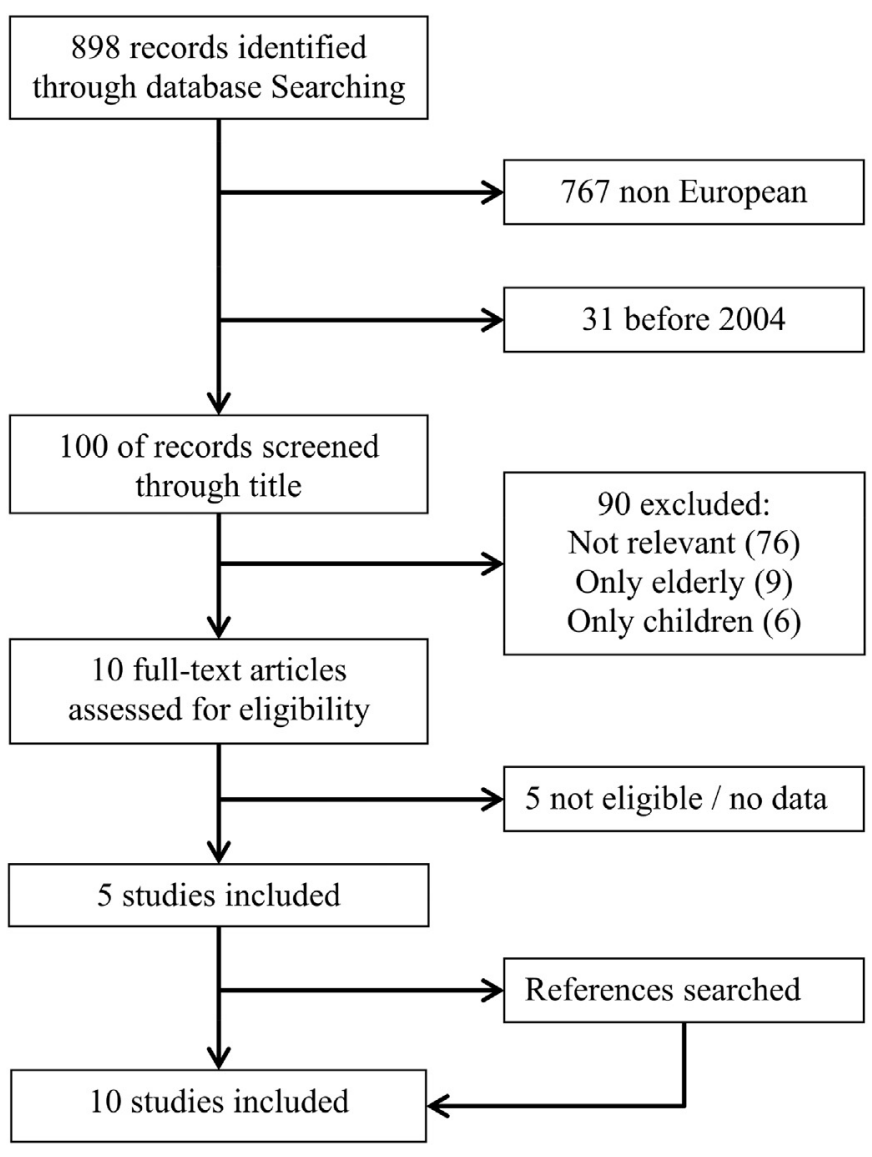

Fig. 1. Selection procedure for the papers on length of stay.

between malnutrition classification (mild, moderate and severe) and prolonged LOS $[11,15]$. In the Switzerland study in 2004, severe malnourished patients had a five-fold increase of LOS compared to well-nourished patients ( $25.8 \pm 60.6$ vs. $5.1 \pm 8.2$ days, respectively) [15].

No clear trend regarding malnutrition prevalence or its impact on LOS was found within the 10 years period. This unchanged prevalence of malnutrition could be due to the increasing age of hospitalized patients [22], which could also impact LOS. Still, the fact that LOS among malnourished patients did not improve during the period analyzed relative to well nourished patients suggests that nutritional interventions in hospitalized patients are not sufficient.

\section{Impact of malnutrition on hospital costs}

Nine papers investigating the economic costs of malnutrition among hospitalized patients were included (selection procedure on Fig. 2). Their main characteristics are summarized in Table 2. Except one study conducted in a Gastroenterology Ward [7] all the others were multidisciplinary [6,7,10,13,15,18,23-25]. For nutritional status, one study used the NRI [15], one the SGA [7], four the NRS-2002 [6,13,18,24], two the Malnutrition Universal Screening Tool (MUST) [23,25] and one used Body Mass Index (BMI) and weight loss [10]. Most malnutrition rates ranged from 19 [7] to 44\% [10], with the exception of the Croatian study, which reported a much lower prevalence (3.37\%) [24]. One paper had data on costs according to malnutrition status, but it was unclear which definition was applied, so it was not included; total costs were $1912 €$ (no 
Table 1

Characteristics of the studies assessing the impact of malnutrition in hospital length of stay.

\begin{tabular}{|c|c|c|c|c|c|c|c|}
\hline \multirow[t]{2}{*}{ Author (ref) } & \multirow[t]{2}{*}{ Country } & \multirow[t]{2}{*}{$\mathrm{N}$} & \multirow[t]{2}{*}{ Nutritional screening tool } & \multirow[t]{2}{*}{ Prevalence of malnutrition (\%) } & \multicolumn{3}{|c|}{ Length of stay (days) } \\
\hline & & & & & Mal-nourished & Well-nourished & Difference \\
\hline Planas et al. [12] & Spain & 400 & SGA & 26.7 & $7.3 \pm 6.2$ & $4.9 \pm 5.1$ & 2.4 \\
\hline \multirow[t]{4}{*}{ Kyle et al. [15] } & Switzerland & 652 & NRI & 24.0 & $10.2 \pm 16.0^{*}$ & $5.1 \pm 8.2$ & 5.1 \\
\hline & Germany & 621 & & & $25.8 \pm 60.6^{* *}$ & $9.1 \pm 7.7$ & 20.7 \\
\hline & & & & & $11.8 \pm 7.7^{*}$ & & 2.7 \\
\hline & & & & & $17.8 \pm 14.7^{* *}$ & & 8.7 \\
\hline Ockenga et al. [7] & Germany & 541 & SGA & 19.0 & $11 \pm 9$ & $7.7 \pm 7$ & 3.3 \\
\hline Pirlich et al. [11] & Germany & 1886 & SGA & 27.4 & $15^{*} / 17^{* *}$ & 11 & 4.6 \\
\hline Nadine et al. [16] & Switzerland & 102 & SGA \& NRS-2002 & 28.0 & 9 & 6 & 3.0 \\
\hline Amaral et al. [6] & Portugal & 469 & NRS-2002 & 42.0 & $14.7 \pm 12.5$ & $7.6 \pm 8.3$ & 7.1 \\
\hline Pressoir et al. [17] & France & 1545 & NR & 30.9 & $19.3 \pm 19.4$ & $13.3 \pm 19.4$ & 6.0 \\
\hline Burgos et al. [14] & Spain & 796 & NRS-2002 & 28.9 & $10.5 \pm 9.5$ & $7.7 \pm 7.8$ & 2.8 \\
\hline Alvarez-Hernández et al. [13] & Spain & 1597 & NRS-2002 & 23.7 & 15.2 & 8.0 & 7.2 \\
\hline Tangvik et al. [18] & Norway & 3271 & NRS-2002 & 29.0 & $8.32 \pm 0.32$ & $5.03 \pm 0.12$ & 3.3 \\
\hline
\end{tabular}

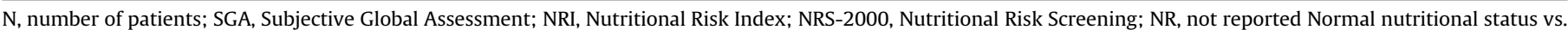
moderate* to severe** malnutrition; All differences between malnourished and well-nourished patients are significant.

standard deviation provided) for well nourished and $2990 €$ for malnourished patients [19].

Most selected studies reported additional costs, defined as the extra cost involved in treating all malnourished patients in the general population compared to treating the same number of wellnourished individuals $[6,7,10,13,18,23,25]$. Five studies reported overall costs [10,15,23-25], and four studies reported detailed costs (hospital, diagnosis, therapies and medications costs) $[6,7,13,15,18]$. Irrespective of the type of costs considered, all studies reported increased hospital costs due to malnutrition (Table 2).

Four studies reported individual data. One study conducted in a gastroenterology ward in Germany reported a 10,268 € additional

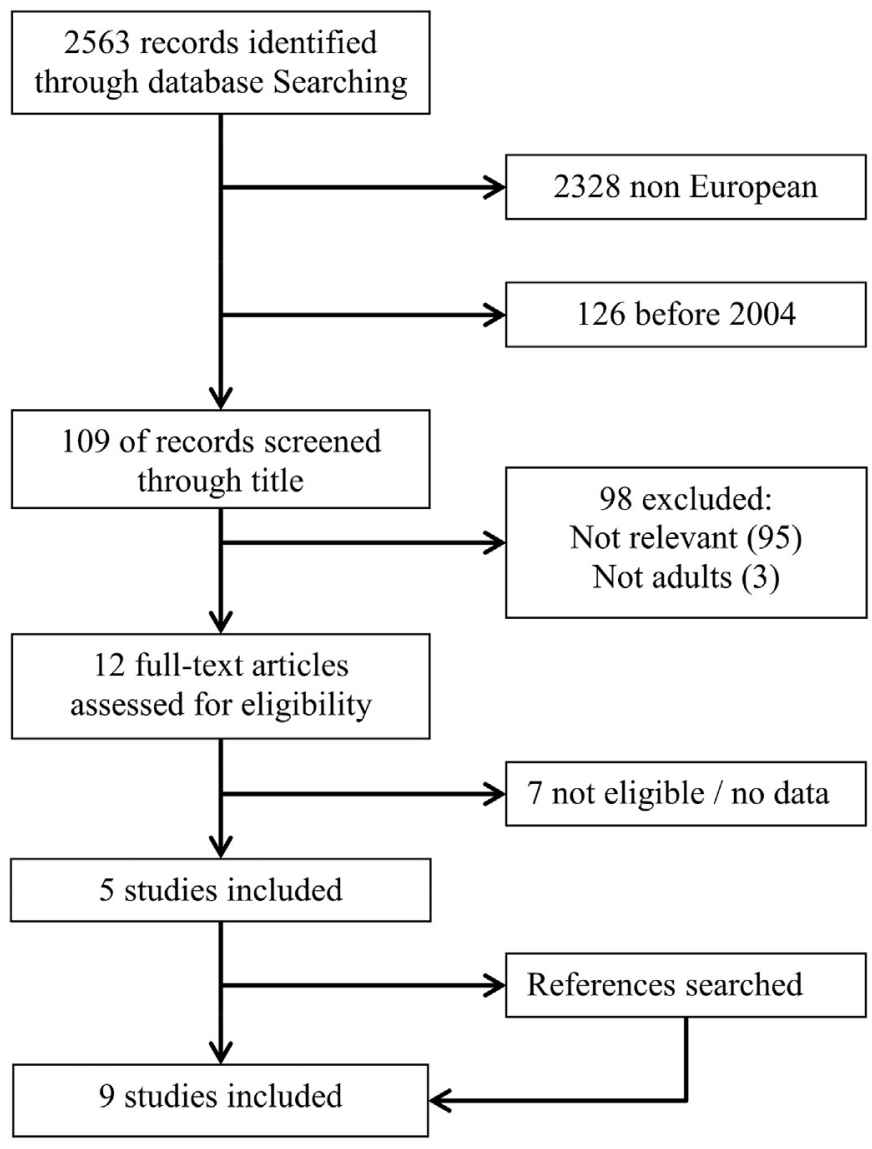

Fig. 2. Selection procedure for the papers on cost of malnutrition. cost for nutritional support (dietary counseling, special diet, oral supplementation and enteral/parenteral feeding) for a group of 50 randomly selected malnourished patients, leading to an average extra cost of $205 €$ per patient [7]. A study conducted in Portugal used diagnosis-related group (DRG) codes and LOS to calculate hospitalization costs [6]. Patients at nutritional risk had hospitalization costs which were twice higher than patients not at risk, with an average additional cost of $2687 €$ [6]. In Spain, costs were calculated based on average hospitalization costs and the nutritional support provided (oral supplementation and enteral/ parental feeding). Malnourished patients at admission had an average additional cost of $1409 €$ compared to well-nourished patients at admission; the difference was even higher (5829 €) between patients well-nourished at admission and malnourished at discharge and well-nourished patients at admission and discharge [13]. Finally, a study conducted in Norway estimated costs based on a mean daily cost for patients ready to discharge and the average LOS in hospital over one year. Malnourished patients had $60 \%$ higher costs than well-nourished patients, corresponding to an additional cost of $4745 €$ per year [18].

Five studies reported costs at the national level. In the study conducted in Switzerland and Germany, hospital costs for malnourished patients were 3.1 times higher than for wellnourished patients [15], but no precise values were provided. In the United Kingdom, the annual health care cost of DRM for hospitalized patients was about 3.7 billion $£(4.7$ billion $€$ ) and the additional cost was almost 3 billion $£$ ( 3.8 billion $€$ ). In Ireland, the annual total public health and social care costs of malnutrition were estimated at 1.4 billion $€(10 \%$ of the national health care budget $)$ in all healthcare settings, of which 72 million $€(5 \%)$ were attributed to hospitalized patients with DRM [23]. In the Netherlands, the total additional costs (prevention, diagnostic, therapy, rehabilitation and care of the disease or treatment under consideration) of DRM were estimated at 1.9 billion $€(2.1 \%$ of the national health expenditure), of which 1.2 billion $€(66 \%)$ were attributed to hospital settings [10]. In Croatia, the total direct costs of malnourished patients were estimated at 97.35 million $€$ (3.38\% of the national health care budget), of which 32.8 million $€(34 \%)$ were attributed to hospital malnutrition, leading to an average cost of malnutrition of $1640.48 €$ per hospitalized patient [24].

\section{Discussion}

Our results indicate that malnutrition carries a considerable economic burden, with an additional cost ranging between 1640 
Table 2

Characteristics of the studies assessing the impact of malnutrition in hospital costs.

\begin{tabular}{|c|c|c|c|c|c|c|c|}
\hline Author & Country & Discipline & $\mathrm{N}$ & Nutritional screening tool & $\begin{array}{l}\text { Study } \\
\text { period }\end{array}$ & Prevalence $(\%)^{\mathrm{a}}$ & Malnutrition related costs \\
\hline \multicolumn{8}{|l|}{ Individual data } \\
\hline Ockenga et al. [7] & Germany & Gastroenterology & 50 & SGA & 1 year & 19.0 & $\begin{array}{l}10,268 € \text { additional cost for } \\
\text { nutritional support among } 50 \text { patients }\end{array}$ \\
\hline Amaral et al. [6] & Portugal & Multidisciplinary & 469 & NRS-2002 & 11 months & 42.0 & $\begin{array}{l}4890 € \text { for malnourished } \\
2201 € \text { for well-nourished } \\
2687 € \text { additional cost }\end{array}$ \\
\hline $\begin{array}{l}\text { Alvarez-Hernández } \\
\text { et al. [13] }\end{array}$ & Spain & Multidisciplinary & 468 & NRS-2002 & 6 months & 24.4 & $\begin{array}{l}12,237 € \text { for malnourished } \\
6798 € \text { for well-nourished } \\
5829 € \text { additional cost }\end{array}$ \\
\hline Tangvik et al. [18] & Norway & Multidisciplinary & 3279 & NRS-2002 & 1 year & 29.0 & $\begin{array}{l}15,394 \$ \text { for malnourished } \\
9460 \$ \text { for well-nourished } \\
5934 \$ \text { ( } 4745 € \text { ) additional cost/year }\end{array}$ \\
\hline \multicolumn{8}{|l|}{ Overall data } \\
\hline Kyle et al. [15] & $\begin{array}{l}\text { Switzerland } \\
\text { Germany }\end{array}$ & Multidisciplinary & $\begin{array}{l}652 \\
621\end{array}$ & NRI & - & 24.0 & $\begin{array}{l}\text { 3.1 times higher in } \\
\text { malnourished vs. well-nourished }\end{array}$ \\
\hline Elia et al. [25] & $\begin{array}{l}\text { United } \\
\text { Kingdom }\end{array}$ & Multidisciplinary & 1.29 million & MUST & 1 year & 28.0 & $\begin{array}{l}\text { Total cost: } 3.7 \text { billion } £(4.7 \text { billion } €) \\
\text { Additional cost: } 3 \text { billion } £ \\
\text { ( } 3.8 \text { billion } € \text { ) annually }\end{array}$ \\
\hline Rice et al. [23] & Ireland & Multidisciplinary & 1602 & MUST & 1 year & 36.3 & $\begin{array}{l}\text { Total cost: } 1.4 \text { billion } € \\
10 \% \text { of the health-care budget } \\
5357 € \text { additional cost of DRM }\end{array}$ \\
\hline Freijer et al. [10] & The Netherlands & Multidisciplinary & 14 million & $\begin{array}{l}\text { BMI }<18.5 \text { OR } \\
-18.5<\mathrm{BMI}<20+3 \text { days of no } \\
\text { food intake or less than normal } \\
\text { during a week or weight loss } \\
\text { of } 6 \mathrm{~kg} \text { in the past } 6 \text { months } \\
\text { or }>3 \mathrm{~kg} \text { in the past month }\end{array}$ & 1 year & 4 to 44 & $\begin{array}{l}\text { Additional } 1.2 \text { billion } € \text { in } \\
\text { hospital setting } \\
66 \% \text { of total expenditures on DRM }\end{array}$ \\
\hline Benković et al. [24] & Croatia & Multidisciplinary & NR & NRS-2002 & 1 year & 3.37 & $\begin{array}{l}\text { Total cost: } 97.35 \text { million } € \text { in one year } \\
3.38 \% \text { of national health care budget } \\
1640 € \text { average cost per patient }\end{array}$ \\
\hline
\end{tabular}

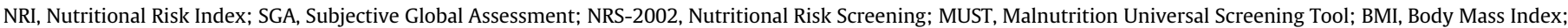
DRM, Disease related malnutrition.

a Prevalence of malnutrition.

and $5829 €$ per hospitalized patient and an overall cost ranging between 2.1 and $10 \%$ of the national health expenditures.

\section{Impact of malnutrition on length of stay}

Malnutrition led to an increased LOS, ranging from 2.4 to 7.2 days. Relative to well-nourished patients, the average LOS increased by $30-100 \%$ in malnourished patients, a value in line with one recent review which also reported 40-70\% longer LOS in malnourished patients [26]. This longer LOS is due to the classic adverse effects of malnutrition such as increased risk of infection or pressure ulcer, impaired wound healing, immune suppression and muscle wasting [27], leading to delayed recovery and increased risk of complications [28]. Indeed, increased LOS is one of the major components of the additional costs related to malnutrition [25]. Conversely, the beneficial effects of nutritional intervention on clinical outcomes of malnutrition have been manifold documented $[28,29]$, leading to a significant reduction of LOS and consequently in total costs [30,31]. Thus, early malnutrition intervention may be really beneficial to improve outcomes and health care costs.

\section{Impact of malnutrition on hospital costs}

Malnutrition led to an additional increase in costs among hospitalized patients ranging between 1640 [24] and $5829 €[13]$ per patient. Taken together, malnutrition-related costs represented between 2.1 and $10 \%$ of the national health expenditure. However, this large difference between two European countries of similar population size and economic wealth is very likely due to the different statistical models and the assumptions used and not the true burden of disease. Thus, malnutrition among hospitalized patients is a far from trivial condition, leading to a considerable health and economic burden. Moreover, the reported costs are likely to be an underestimate as not all increased treatment costs were included [24].

While the consequences of malnutrition on health have been documented in a large number of studies, the number of studies assessing the economic impact of malnutrition is considerably smaller. It is also important to mention that harmonizing and comparing the results between studies and countries is difficult, due to differences in health care systems, cost calculations and reporting monetary units $(£, \$, €)$. For instance, some studies used administrative data [6], while others assessed directly the costs of nutritional therapy [7]; some studies reported total costs while others reported extra costs at admission and/or discharge. Hence, it would be of interest that future studies on the costs of malnutrition use a standard definition of malnutrition and indicate how the differences between well-nourished and malnourished patients were computed. It is also important that studies report their results in a standardized manner: although monetary units (i.e. $€$ ) might be important for local health administrators, they might not be of much help for other countries as health costs vary between countries. Thus, other cost-related units could be used, such as LOS, nutrition interventions (i.e. number of nutritional supplements used, enteral/parental nutrition, and consultations by dieticians ...) or DRGs. Still, it should be noted that the DRG system changes slightly between countries so that direct comparisons might not be achievable [32]. Further, as some DRGs change according to presence/absence of malnutrition, it would be important to include malnutrition diagnosis codes in the patients' file in order to better evaluate the real economic burden related to malnutrition. 
Despite the different methods used to estimate malnutritionrelated hospitalization costs, all studies indicate that the total costs of malnutrition are extremely important and largely outweigh those related to obesity $[5,25]$. Thus, screening at admission and early treatment of malnutrition could lead to considerable health savings [5,31,33]. Indeed, Elia et al. (2005) reported that an investment of 5 million $£(6.4$ million $€)$ in nutritional intervention would result in a saving of 50 million $£$ ( 63.7 million $€$ ) per year, corresponding to a $1 \%$ reduction in malnutrition-related costs.

\section{Limitations}

This review has several limitations. Firstly, no data were available for many European countries. This was somewhat unexpected for some countries such as Denmark, Sweden and Finland, as their health data management system would facilitate such calculations, at least regarding the costs of nutritional therapy. Thus, it is difficult to determine the impact of malnutrition on medical economic outcomes for a most European countries. Secondly, several definitions of malnutrition were applied, possibly leading to different prevalence rates and thus different costs. Still, our results suggest that malnutrition is associated with increased hospitalization costs irrespective of the definition applied. Thirdly, each study used its own cost assessment method, thus precluding direct comparison of results. Indeed, the heterogeneity of the cost calculations in the individual studies, such as cost of hospitalization vs. cost of nutritional treatment or calculation for a small patient group vs. for a whole country, is a main limitation of this paper. We thus believe that the recommendations for reporting results provided above will facilitate comparison of future studies.

\section{Conclusion}

In Europe, the economic impact of hospital malnutrition is considerable, both at the individual and the national level. Standardization of methods and results reported is badly needed to adequately compare results between countries.

\section{Names for PubMed indexing}

Saman Khalatbari-Soltani (Khalatbari-Soltani S), Pedro Marques-Vidal (Marques-Vidal P).

\section{Funding}

Saman Khalatbari Soltani is supported by a Swiss Excellence Government scholarship awarded by Swiss Confederation.

\section{Conflict of interest}

none.

\section{Competing interests}

All authors declare no competing interests.

\section{Acknowledgments}

The authors' responsibilities were as follows-SKS: performed the literature search, prepared the tables and drafted the manuscript. PMV: conceived the study, participated in its design and coordination and helped to draft the manuscript. All authors read and approved the final manuscript.

\section{Appendix A. Supplementary data}

Supplementary data related to this article can be found at http:// dx.doi.org/10.1016/j.clnesp.2015.04.003.

\section{References}

[1] Agarwal E, Ferguson M, Banks M, Batterham M, Bauer J, Capra S, et al. Malnutrition and poor food intake are associated with prolonged hospital stay, frequent readmissions, and greater in-hospital mortality: results from the nutrition care day survey 2010. Clin Nutr 2013;32(5):737-45.

[2] Elia M, Russell CA, Stratton RJ. Malnutrition in the UK: policies to address the problem. In: Proceedings of the nutrition society69(04); 2010. p. 470-6.

[3] Stratton RJ, Green CJ, Elia M. Disease-related malnutrition: an evidence-based approach to treatment. Oxford: CABI International; 2003. p. 824.

[4] Goiburu ME, Goiburu MM, Bianco H, Diaz JR, Alderete F, Palacios MC, et al. The impact of malnutrition on morbidity, mortality and length of hospital stay in trauma patients. Nutr Hosp 2006;21(5):604-10.

[5] Elia M, Russell CA. Combating malnutrition: recommendations for actions. In: Report from the group on malnutrition; 2009. Led by BAPEN.

[6] Amaral TF, Matos LC, Tavares MM, Subtil A, Martins R, Nazaré M, et al. The economic impact of disease-related malnutrition at hospital admission. Clin Nutr 2007;26(6):778-84.

[7] Ockenga J, Freudenreich M, Zakonsky R, Norman K, Pirlich M, Lochs H. Nutritional assessment and management in hospitalised patients: implication for DRG-based reimbursement and health care quality. Clin Nutr 2005;24(6): 913-9.

[8] Isabel TD, Correia M, Waitzberg DL. The impact of malnutrition on morbidity, mortality, length of hospital stay and costs evaluated through a multivariate model analysis. Clin Nutr 2003;22(3):235-9.

[9] Ljungqvist O, van Gossum A, Sanz ML, de Man F. The European fight against malnutrition. Clin Nutr 2010;29(2):149-50.

[10] Freijer K, Tan SS, Koopmanschap MA, Meijers JMM, Halfens RJG, Nuijten MJC. The economic costs of disease related malnutrition. Clin Nutr 2013;32(1): $136-41$.

[11] Pirlich M, Schütz T, Norman K, Gastell S, Lübke HJ, Bischoff SC, et al. The German hospital malnutrition study. Clin Nutr 2006:25(4):563-72.

[12] Planas M, Audivert S, Pérez-Portabella C, Burgos R, Puiggrós C, Casanelles JM, et al. Nutritional status among adult patients admitted to an universityaffiliated hospital in Spain at the time of genoma. Clin Nutr 2004;23(5): $1016-24$.

[13] Álvarez-Hernández J, Planas Vila M, León-Sanz M, García de Lorenzo A, Celaya-Pérez S, García-Lorda P, et al. Prevalence and costs of malnutrition in hospitalized patients: the PREDyCES ${ }^{\circledR}$ study, Nutr Hosp 2012:27:1049-59.

[14] Burgos R, Sarto B, Elío I, Planas M, Forga M, Cantón A, et al. Prevalence of malnutrition and its etiological factors in hospitals. Nutr Hosp 2012;27: 469-76.

[15] Kyle U, Pirlich M, Schuetz T, Lochs H, Pichard C. Is nutritional depletion by nutritional risk index associated with increased length of hospital stay? A population-based study. JPEN 2004;28(2):99-104.

[16] Nadine G, Reinhard I, Marlene W, Maya R, Peter EB. Serumalbumin-a qualified parameter to determine the nutritional status? Swiss Med Wkly 2006;136(41-42):664-9.

[17] Pressoir M, Desne S, Berchery D, Rossignol G, Poiree B, Meslier M, et al. Prevalence, risk factors and clinical implications of malnutrition in French comprehensive cancer centres. Br J Cancer 2010;102(6):966-71.

[18] Tangvik RJ, Tell GS, Eisman JA, Guttormsen AB, Henriksen A, Nilsen RM, et al. The nutritional strategy: four questions predict morbidity, mortality and health care costs. Clin Nutr 2014;33(4):634-41.

[19] de la Cruz AP, Lobo Támer G, Orduña Espinosa R, Mellado Pastor C, Aguayo de Hoyos E, Ruiz López MD. Desnutrición en pacientes hospitalizados: prevalencia e impacto económico. Titlerevista 2004;123(06):201-6.

[20] Ray S, Laur C, Golubic R. Malnutrition in healthcare institutions: a review of the prevalence of under-nutrition in hospitals and care homes since 1994 in England. Clin Nutr 2014;33(5):829-35.

[21] Sorensen J, Kondrup J, Prokopowicz J, Schiesser M, Krähenbühl L, Meier R, et al. EuroOOPS: an international, multicentre study to implement nutritional risk screening and evaluate clinical outcome. Clin Nutr 2008;27(3):340-9.

[22] Kyle UG, Genton L, Pichard C. Hospital length of stay and nutritional status. Curr opin Clin nutr metabol care 2005;8(4):397-402.

[23] Rice N, Normand C. The cost associated with disease-related malnutrition in Ireland. Public Health Nutr 2012:1-7.

[24] Benković V, Kolčić I, Ivičević Uhernik A, Vranešić Bender D, Oreb I, Stevanović R, et al. The economic burden of disease-related undernutrition in selected chronic diseases. Clin Nutr 2014;33(4):689-93.

[25] Elia M, Stratton RJ, Russell CA, Green CJ, Pang F. The cost of disease-related malnutrition in the UK and economics considerations for the use of oral nutritional supplements (ONS) in adults. In: A report by the health economic group of the British association for parental and enteral nutrition (BAPEN). UK; 2005. BAPEN.

[26] Norman K, Pichard C, Lochs H, Pirlich M. Prognostic impact of disease-related malnutrition. Clin Nutr 2008;27(1):5-15. 
[27] Tappenden KA, Quatrara B, Parkhurst ML, Malone AM, Fanjiang G, Ziegler TR. Critical role of nutrition in improving quality of care: an interdisciplinary call to action to address adult hospital malnutrition. J Acad Nutr Diet 2013;113(9): $1219-37$.

[28] Cawood AL, Elia M, Stratton RJ. Systematic review and meta-analysis of the effects of high protein oral nutritional supplements. Ageing Rese Rev 2012;11(2):278-96.

[29] Somanchi M, Tao X, Mullin GE. The facilitated early enteral and dietary management effectiveness trial in hospitalized patients with malnutrition. JPEN 2011;35(2):209-16.
[30] Kruizenga HM, Van Tulder MW, Seidell JC, Thijs A, Ader HJ, Van Bokhorst-de van der Schueren MA. Effectiveness and cost-effectiveness of early screening and treatment of malnourished patients. Am J Clin Nutr 2005;82(5):1082-9.

[31] Tucker HN, Miguel SG. Cost containment through nutrition intervention. Nutr Rev 1996;54(4 Pt 1):111-21.

[32] Tan SS, Geissler A, Serden L, Heurgren M, van Ineveld BM, Redekop WK, et al. DRG systems in Europe: variations in cost accounting systems among 12 countries. Euro J Pub Health 2014;24(6):1023-8.

[33] Lee C, Rucinski J, Bernstein L. A systematized interdisciplinary nutritional care plan results in improved clinical outcomes. Clin Biochem 2012;45(15):1145-9. 